\title{
Fatigue Properties of Plain Concrete under Triaxial Tension-Compression-Compression Cyclic Loading
}

\author{
Dongfu Zhao, ${ }^{1,2}$ Haijing Gao, ${ }^{2}$ Huixuan Liu, ${ }^{2}$ Penghe Jia, ${ }^{2}$ and Jianhui Yang $^{3}$ \\ ${ }^{1}$ Beijing Higher Institution Engineering Research Center of Structural Engineering and New Materials, \\ Beijing University of Civil Engineering and Architecture, Zhanlanguan Road No. 1, Beijing 100044, China \\ ${ }^{2}$ School of Civil and Transportation Engineering, Beijing University of Civil Engineering and Architecture, Zhanlanguan Road No. 1, \\ Beijing 100044, China \\ ${ }^{3}$ School of Civil Engineering, Henan Polytechnic University, No. 2001, Century Avenue, New District, Jiaozuo 454000, China \\ Correspondence should be addressed to Haijing Gao; baboon007@126.com
}

Received 10 November 2016; Revised 8 January 2017; Accepted 1 February 2017; Published 21 February 2017

Academic Editor: Paulo B. Gonçalves

Copyright (c) 2017 Dongfu Zhao et al. This is an open access article distributed under the Creative Commons Attribution License, which permits unrestricted use, distribution, and reproduction in any medium, provided the original work is properly cited.

Fatigue tests were performed on plain concrete under triaxial tension-compression-compression (T-C-C) cyclic loading with constant and variable amplitude using a large multiaxial machine. Experimental results show that, under constant amplitude fatigue loads, the development of residual strain in the fatigue loading direction depends mostly on the lateral compressive stress ratio and is nearly independent of stress level. Under variable amplitude fatigue loads, the fatigue residual strain is related to the relative fatigue cycle and lateral compressive stress ratio but has little relationship with the loading process. To model this system, the relative residual strain was defined as the damage variant. Damage evolutions for plain concrete were established. In addition, fatigue damage analysis and predictions of fatigue remaining life were conducted. This work provides a reference for multistage fatigue testing and fatigue damage evaluation of plain concrete under multiaxial loads.

\section{Introduction}

In practice, many concrete structures such as offshore platforms, nuclear reactor pressure containers, and bridges are subjected to repeated loading amplitudes in complex multiaxial stress states during normal use. Thus, it is important to understand fatigue damage accumulation in concrete under multiaxial variable amplitude stresses and various stress ratios. In the last few decades, many researches have been carried out to study the fatigue properties of plain concrete (PC) under uniaxial and multiaxial compressive loads. Because the development of multiaxial fatigue test system technology is difficult and with high cost and several key technical problems exist in the experiment, to date, a few works have been dedicated to investigating multiaxial tension and compression fatigue properties. Park et al. [1] used thin fire-damaged concrete discs to evaluate tensile strength and found that the tensile strength could be effectively estimated from the HNP without consideration of the mix proportion. He et al. [2,3] focused on the multiaxial mechanical properties of plain recycled aggregate concrete (RAC) and found that the ratio of triaxial fatigue strength to the corresponding uniaxial compressive strength for the three strength grades of RAC was higher than that of conventional concrete. Mun et al. [4] examined the fatigue stress-strain response of different concrete mixtures under compressive cyclic loadings with maximum and minimum stress levels. Shi et al. [5] reported that the tensile strength and secant modulus of large aggregate concrete under triaxial T-C-C increase with the increase of strain rate but decrease with the increase of lateral compressive stress. Subramaniam et al. [6] studied the fatigue behavior of concrete subjected to combined stresses in the $\mathrm{T}-\mathrm{C}$ region of the biaxial stress space and found that the decrease in rotational stiffness at failure for the constant amplitude fatigue loading was comparable to the corresponding load in the postpeak part of the quasistatic response. Shiming and Yupu [7] studied on biaxial $\mathrm{T}-\mathrm{C}$ strength and found that tensile compressive strength 
increases with the increase of strain rate when the lateral tensile stress is constant and the tensile compressive strength decreases with the increase of lateral tensile stress. Yan et al. [8] tested the dynamic properties of concrete materials under both high strain rates and triaxial stress states. It was pointed out that the strain rate effects on maximum strength under triaxial stress states decrease with an increase in confining stress. Only Yang et al. [9] investigated the fatigue properties of concrete in tension under single and bilateral pressure of variable amplitude, determining fatigue life and residual strain. Based on the cyclic stress-strain curve, fatigue deformation modulus was defined. Accordingly, a damage model was established through the relationship between the ratios of fatigue deformation modulus and the number of cycles. Above all, we can see that the researches on plain concrete for fatigue properties under triaxial T-C-C loading are rare, so it has a realistic significance for us.

Fatigue cumulative damage is one of the main concerns when using PC, and the P-M linear fatigue cumulative damage criterion is still the most widely used model. On this basis, most studies have included research on the linear damage of PC. Studies have validated and discussed the damage variant $D=\sum\left(n_{i} / N_{i}\right)$. Subramaniam et al. [6] recommended that damage in concrete subjected to biaxial fatigue loading in the T-C region through torsion is localized, the damage localizes to a single crack, and the observed overall response is governed by crack growth. The loaddeformation response obtained from quasistatic loading acts as the envelope failure curve for fatigue loading considering decrease in rotational stiffness. Peiyin et al. [10] discussed the laws and characteristics of fatigue residual strain, defined the damage variable, and carried out damage accumulation and evolution rules. In addition, a model of fatigue damage was established and verified using experimental results. These investigations focused on the nonlinear cumulative fatigue damage to concrete. The fatigue damage evolution equations were defined using other parameters such as strain, strength, and elastic modulus as part of the damage variant. Chen et al. [11] reported the effects of stress state on the dynamic compressive strength and the dynamic damage evolution process of concrete using a split Hopkinson pressure bar and ultrasonic technique. Results showed that dynamic damage evolutions are accelerated with an increase in strain rate and are delayed significantly under confined pressure. Byung [12] introduced the cumulative damage theory of concrete under variable amplitude fatigue loading condition. Yang et al. [9] investigated the properties of concrete in tension under single and bilateral pressure of variable amplitude fatigue, working out fatigue life and residual strain. Based on the cyclic stress-strain curve, fatigue deformation modulus was defined. Accordingly, a damage model was established through the relationship between the ratios of fatigue deformation modulus and the number of cycles. Cao et al. [13] considered more than the fatigue residual strain of concrete when determining the damage variant. Steady deformations and smaller discreteness at the ultimate residual strain were observed when considering residual strain on the concrete fatigue loading direction. Thus, the unrecoverable degree of microplastic deformation and microcracks can be determined. This model better reflects the properties of the material than the method of maximum strain for concrete in the fatigue loading direction.

Testing of the triaxial T-C-C fatigue properties was performed using a triaxial testing machine capable of developing three independent compressive or tensile forces at Dalian University of Technology. Fatigue residual strain was recorded during both constant and varying amplitude fatigue processes. The relative residual strain was defined as the damage variant, updates were proposed to the corresponding fatigue damage equation, and the multistage fatigue damage model under triaxial T-C-C loading was established. This work provides a reference for multistage fatigue testing and fatigue damage evaluation of concrete under multiaxial loads.

\section{Materials and Experimental Procedures}

2.1. Casting and Curing of Specimens. The constituent proportions within the mix used experimentally were cement: sand: stone: water $=383: 663: 1154: 193\left(\mathrm{~kg} / \mathrm{m}^{3}\right)$. During testing, the ends of the specimen bulk and the testing machine load head were connected by tightening nuts. This transmitted the tensile strength of the machine through the screw, which was then passed to the specimen in order to test volatility in tension fatigue loading. Specimens were created by casting in wooden molds and compacted slightly by a vibrating table. After 24 hours, specimens were removed from molds and then cured at $20 \pm 3^{\circ} \mathrm{C}$ and $95 \%$ relative humidity for 28 days covered with grass. Specimens were tested 90 days after cure by the test method of Chinese standard GB/T 17671-1999 [14].

Variable cross-section prism specimens were used for testing based on experimental requirements, fatigue performance, specimen installation, and references available at home and abroad. As shown in Figure 1, lateral pressure can be applied to two pairs of sides when testing a prism shaped specimen. The specimens tested measured $150 \mathrm{~mm} \times 150 \mathrm{~mm}$ $\times 350 \mathrm{~mm}$. In order to reduce stress concentrations, both ends of the specimen were embedded with four $\Phi 16$ steel screws, and the end of the screw was embedded within the specimen by $\Phi 8$ steel welded connections. The same batch of concrete was used to create six or more $150 \mathrm{~mm} \times 150 \mathrm{~mm} \times 150 \mathrm{~mm}$ standard cubes, which were used to measure the strength for multiaxial tests and determine strength class [15].

2.2. Testing Load Patterns. Fatigue tests were performed on plain concrete subjected to constant and variable amplitude triaxial T-C-C cyclic loading, and the lateral pressure stresses $S_{\max }$ are $0.25 f_{t}$ and $0.50 f_{t} . S$ is the stress level of fatigue, $S_{\max }=\sigma_{\max } / f_{t}, S_{\min }=\sigma_{\min } / f_{t}=0.10$, and $f_{t}$ is the uniaxial tensile strength of $150 \mathrm{~mm} \times 150 \mathrm{~mm} \times 300 \mathrm{~mm}$ prism. Constant amplitude fatigue of maximum stress was varied from $0.25 f_{t}$ to $0.75 f_{t}$, and variable amplitude fatigue procedures included tests with two and three stages. The loading mode is shown in Figure 2, where loading frequency was $5 \mathrm{~Hz}$. Cyclic loading was applied using a sine wave waveform and the minimum stress level. Load patterns are shown in Table 1. 


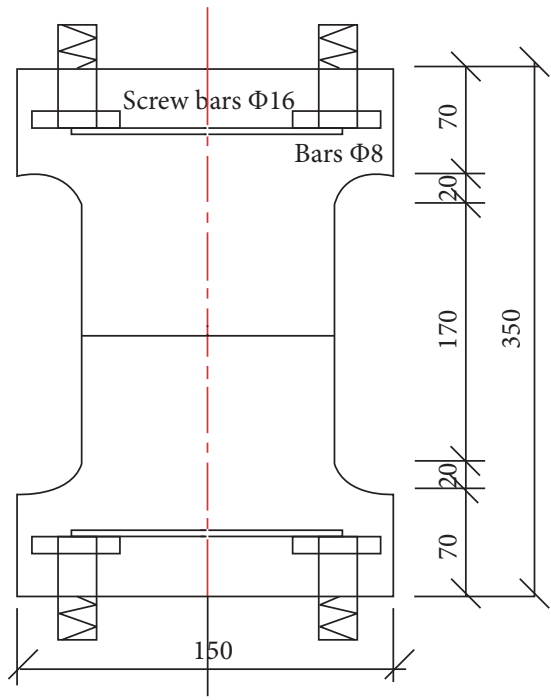

(a) Specimen size and shape

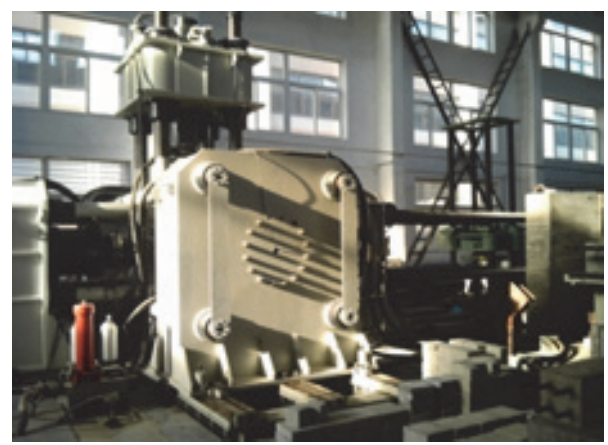

(b) The large-scale static and dynamic multiaxial testing machine

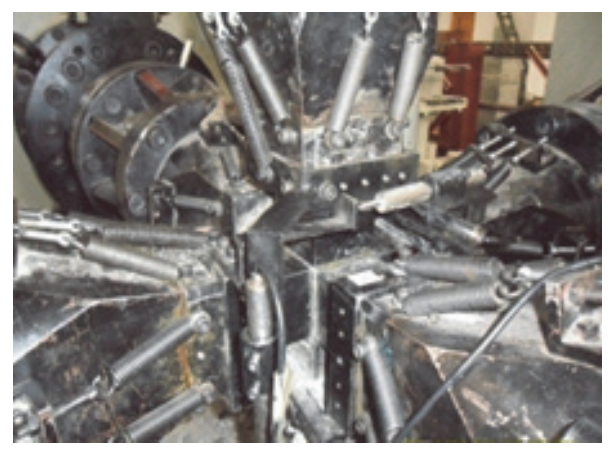

(c) Specimens under multiaxial loads

Figure 1: Machine and specimen.

TABLE 1: Test results for constant-amplitude cyclic loading.

\begin{tabular}{|c|c|c|c|c|c|c|c|c|}
\hline \multicolumn{2}{|c|}{ Lateral stress ratio } & \multirow{2}{*}{$S_{\max }$} & \multicolumn{6}{|c|}{ Fatigue life } \\
\hline$\sigma_{2} / f_{c}$ & $\sigma_{3} / f_{c}$ & & & $N_{f}$ & & & $\bar{N}_{f}$ & \\
\hline \multirow{3}{*}{0.25} & \multirow{3}{*}{0.25} & 0.75 & 210 & 121 & 89 & 75 & 43 & 108 \\
\hline & & 0.65 & 16188 & 8903 & 5117 & 1547 & 369 & 6425 \\
\hline & & 0.55 & 950477 & 783912 & 361760 & 137334 & 32729 & 453242 \\
\hline \multirow{3}{*}{0.25} & \multirow{3}{*}{0.50} & 0.60 & 171 & 102 & 72 & 46 & 21 & 82 \\
\hline & & 0.50 & 20387 & 9753 & 7415 & 1110 & 336 & 7800 \\
\hline & & 0.40 & 1453275 & 1150119 & 785733 & & & 1129709 \\
\hline \multirow{3}{*}{0.50} & \multirow{3}{*}{0.50} & 0.45 & 1276 & 871 & 625 & 389 & 207 & 674 \\
\hline & & 0.35 & 348663 & 150744 & 98146 & 51405 & 17592 & 133310 \\
\hline & & 0.25 & & & & & & \\
\hline
\end{tabular}

Note. $\bar{N}_{f}$ is the average fatigue life.

2.3. Testing Methods. Deformation of the specimen was recorded within a range of $\pm 5 \mathrm{~mm}$ using displacement sensors. Three layers of plastic membrane with Mobil lubricants were placed between the compressive loading plate and the specimen as friction-reducing pads $[2,3]$. After the specimen was placed in the appropriate position, first execute visual alignment and preload $10 \mathrm{kN}$ static load in the vertical direction. Moreover, a larger static load was applied on specimens to complete the horizontal direction centering controlling. Then, preload the same proportion more than three times repeatedly in three directions, so that specimen with the loading plate contact surface compaction and load 


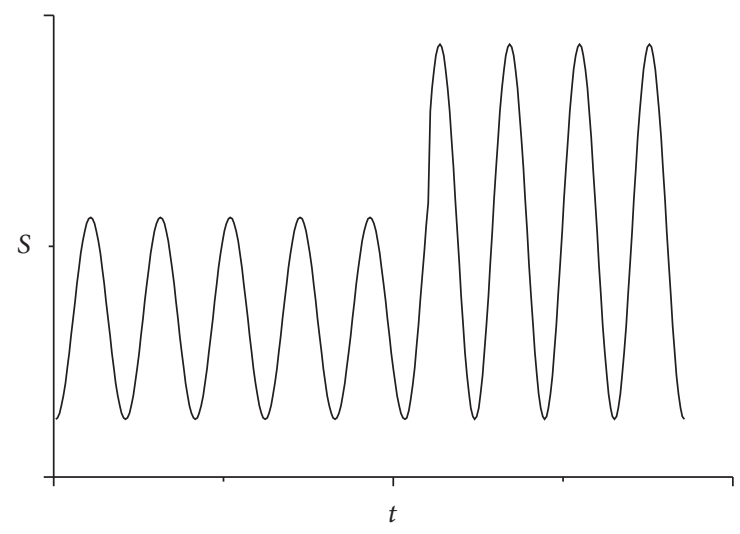

(a) Low-high load pattern

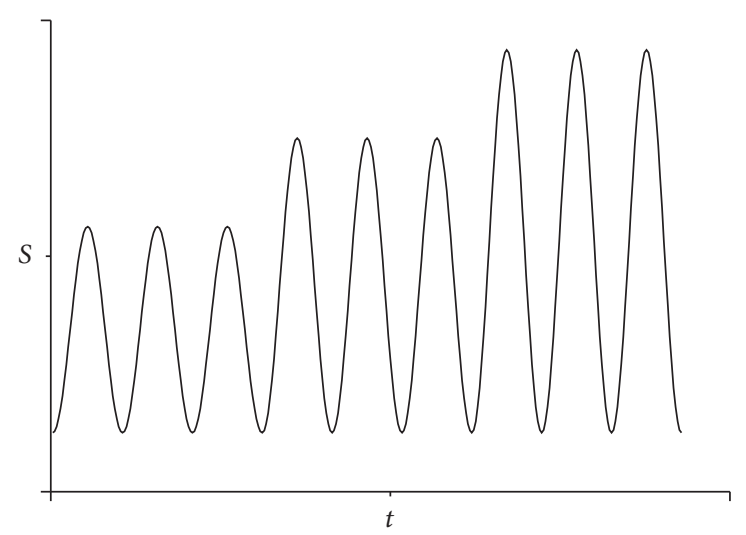

(c) Low-mid-low load pattern

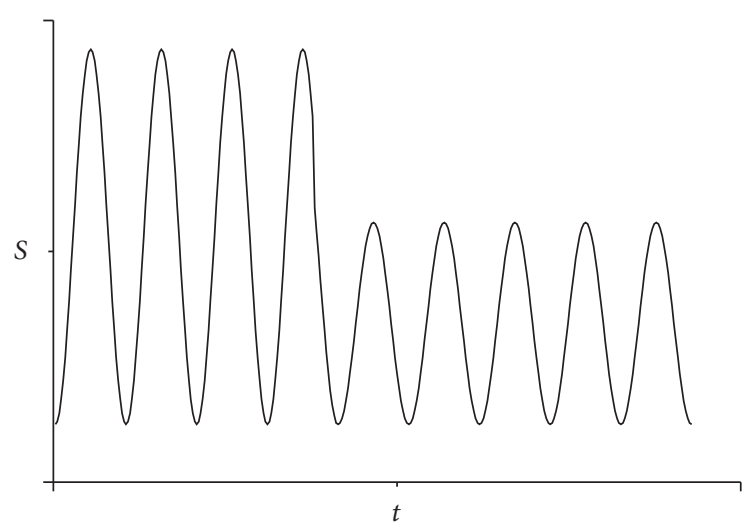

(b) High-low load pattern

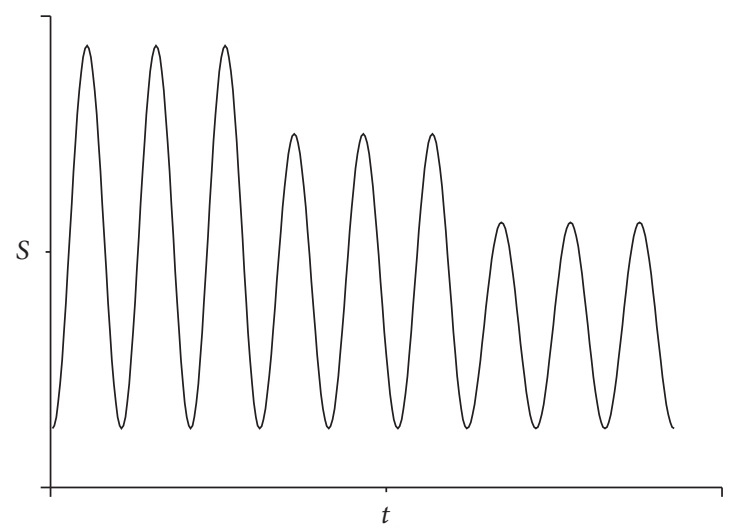

(d) High-mid-low load pattern

FIGURE 2: Load patterns of variable amplitude multistage fatigue tests.

can be appropriately increased to $20 \sim 30 \mathrm{kN}$. Complete the specimen in the geometric centering controlling and fix it with moderate force, gradually tightening evenly eight screws at the upper and lower edges of the specimen. Finally, use a small hammer to tap specimen or load head, through the rotation of globe hinge to adjust mechanical alignment of specimen [16].

\section{Test Results and Discussions}

3.1. Fatigue Life. Fatigue life was measured on plain concrete and results are shown in Tables 1 and 2. A large number of studies have shown that the fatigue strength of concrete is usually attributed to the establishment of $S-N$ curve equation (also known as Wöhler equation). The $S-N$ curve quantitatively describes the relationship between stress level $S$ and fatigue life $N$, and the mathematical expression is

$$
S_{\max }=A-B \lg N,
$$

where $A$ and $B$ are coefficients. And fatigue $S-N$ equations under T-C-C constant amplitude loading at various lateral pressures were analyzed using the linear regression method proposed below:

$$
\begin{array}{r}
S_{\max }=-0.0519 \lg N+0.8388 \\
\left(\frac{\sigma_{2}}{f_{c}}=0.25 ; \frac{\sigma_{3}}{f_{c}}=0.25\right), \\
S_{\max }=-0.0427 \lg N+0.6642 \\
\left(\frac{\sigma_{2}}{f_{c}}=0.25 ; \frac{\sigma_{3}}{f_{c}}=0.50\right), \\
S_{\max }=-0.0412 \lg N+0.5582 \\
\left(\frac{\sigma_{2}}{f_{c}}=0.50 ; \frac{\sigma_{3}}{f_{c}}=0.50\right),
\end{array}
$$

where $S_{\max }$ is the maximum stress level of fatigue, $N$ is fatigue life, $f_{c}$ is uniaxial compressive strength of a concrete prism, $\sigma_{1}$ is the cyclic tensile stress, $\sigma_{2}$ and $\sigma_{3}$ are lateral compressive stresses, $\sigma_{3}<\sigma_{2}<\sigma_{1}$, and the compressive stress is negative but tensile stress is positive. The correlation coefficients $R^{2}$ of the above equations are $0.945,0.965$, and 0.948 , respectively. Figure 3 shows the corresponding $S-N$ scattergram. 
TABLE 2: Test data of fatigue for variable amplitude.

\begin{tabular}{|c|c|c|c|c|c|c|c|c|c|c|}
\hline \multirow{2}{*}{ Specimen number } & \multicolumn{2}{|c|}{ Fatigue life } & \multirow{2}{*}{$D$} & \multirow{2}{*}{$\begin{array}{l}\varepsilon_{0} \\
\mu \varepsilon\end{array}$} & \multirow{2}{*}{ Specimen number } & \multicolumn{3}{|c|}{ Fatigue life } & \multirow{2}{*}{$D$} & \multirow{2}{*}{$\begin{array}{l}\varepsilon_{0} \\
\mu \varepsilon\end{array}$} \\
\hline & $n_{1}$ & $n_{2}$ & & & & $n_{1}$ & $n_{2}$ & $n_{3}$ & & \\
\hline 25250101 & 52203 & 24 & 0.45 & 215 & 25250301 & 52203 & 1004 & 121 & 1.79 & 255 \\
\hline 25250102 & 52203 & 308 & 3.48 & 234 & 25250302 & 52203 & 1004 & 75 & 1.30 & 248 \\
\hline 25250103 & 52203 & 272 & 3.09 & 238 & 25250303 & 52203 & 1004 & 13 & 0.64 & 192 \\
\hline 25250104 & 52203 & 43 & 0.66 & 247 & 25250304 & 52203 & 1004 & 360 & 4.33 & 244 \\
\hline 25250105 & 52203 & 640 & 7.01 & 204 & 25250305 & 52203 & 1004 & 29 & 0.81 & 232 \\
\hline 25250201 & 19 & 816980 & 3.33 & 217 & 25250401 & 19 & 1004 & 1498232 & 6.24 & 234 \\
\hline 25250202 & 19 & 185321 & 0.91 & 213 & 25250402 & 19 & 1004 & 300168 & 1.65 & 229 \\
\hline 25250203 & 19 & 114847 & 0.64 & 225 & 25250403 & 19 & 1004 & 70474 & 0.77 & 203 \\
\hline 25250204 & 19 & 91356 & 0.55 & 199 & 25250404 & 19 & 1004 & 49593 & 0.69 & 237 \\
\hline 25250205 & 19 & 1934129 & 7.61 & 243 & 25250405 & 19 & 1004 & 109627 & 0.92 & 226 \\
\hline 25500101 & 304705 & 110 & 1.86 & 327 & 25500301 & 304705 & 1060 & 67 & 1.52 & 308 \\
\hline 25500102 & 304705 & 17 & 0.45 & 319 & 25500302 & 304705 & 1060 & 315 & 5.27 & 314 \\
\hline 25500103 & 304705 & 43 & 0.85 & 313 & 25500303 & 304705 & 1060 & 16 & 0.74 & 301 \\
\hline 25500104 & 304705 & 233 & 3.73 & 306 & 25500304 & 304705 & 1060 & 32 & 0.99 & 335 \\
\hline 25500105 & 304705 & 59 & 1.09 & 286 & 25500305 & 304705 & 1060 & 143 & 2.67 & 327 \\
\hline 25500201 & 13 & 2559519 & 1.88 & 310 & 25500401 & 13 & 1060 & 594174 & 0.89 & 334 \\
\hline 25500202 & 13 & 700821 & 0.66 & 302 & 25500402 & 13 & 1060 & 1218818 & 130 & 305 \\
\hline 25500203 & 13 & 594174 & 0.59 & 275 & 25500403 & 13 & 1060 & 289469 & 0.69 & 307 \\
\hline 25500204 & 13 & 1767287 & 1.36 & 293 & 25500404 & 13 & 1060 & 319940 & 0.71 & 320 \\
\hline 25500205 & 13 & $>2500000$ & $>1.88$ & 319 & 25500405 & 13 & 1060 & $>2500000$ & $>2.14$ & 261 \\
\hline 50500101 & 17171 & 1057 & 2.08 & & 50500201 & 112 & & 340844 & 4.17 & 400 \\
\hline
\end{tabular}

Note. $D=\sum\left(n_{i} / N_{i}\right), \varepsilon_{0}$ is the ultimate strain of specimen damage. Specimen numbering methods xxyyzztt: xxyy means the two directions of lateral compressive stress ratio, where 2550 indicates that one direction of lateral compressive stress ratio $\sigma_{2} / f_{c}$ is 0.25 , another $\sigma_{3} / f_{c}$ is 0.50 ; zz represents the amplitude loading condition; 01, 02, 03, and 04 are four testing loading conditions for low-high, high-low, low-medium-high, and high-medium-low, respectively; tt represents the sample number to each operating mode.

3.2. Linear Fatigue Damage Analysis. Miner [17] performed pioneering work on the amplitude fatigue linear cumulative damage rule, the P-M criterion as shown below:

$$
D=\sum_{i=1}^{k} D_{i}=\sum_{i=1}^{k} \frac{n_{i}}{N_{i}}=1 .
$$

In this paper, Miner experimentally verified the P-M criterion. Table 3 shows the values obtained by this work.

As shown in Table 3, our experimental result for the value of $D$ is higher than predicted. However, considering factors that influence multiaxial fatigue, the values of $D$ obtained can be considered within the normal range. Moreover, results indicate that the P-M criterion for multiaxial amplitude fatigue has certain limitations. These limitations are mainly caused by difficulty in satisfying the prerequisites of the principle, which are as follows: each cycle of the energy dissipation is equal under constant amplitude stress level, cumulative damage cannot be influenced by the past loading process, and the fatigue life of concrete would not be affected by variable amplitude loading order.

\section{Nonlinear Damage Analysis}

4.1. Residual Strain. Residual strains were measured during strain development along the fatigue loading direction, and

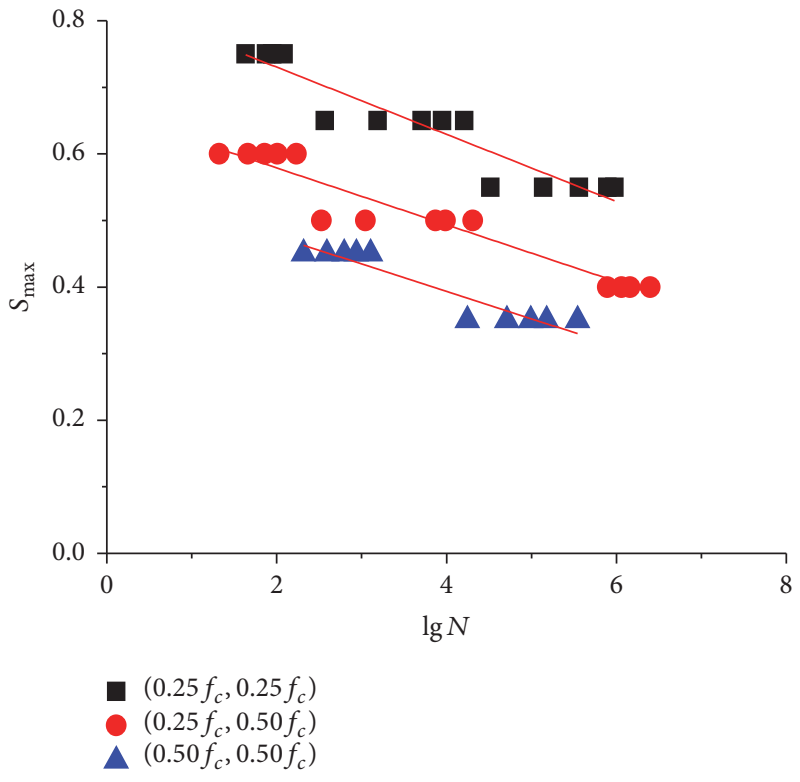

FIgURE 3: $S$-N Scatter-gram.

results are shown in Figures 4 and 5. As shown, under triaxial T-C-C constant amplitude cyclic loading, the development of residual strain of plain concrete in the fatigue 
TABle 3: Value $D$.

\begin{tabular}{lccccc}
\hline & {$[10]$} & {$[20]$} & {$[21]$} & {$[12]$} & \\
\hline Max & 2.94 & 95.72 & 1.11 & 3.26 & This paper \\
Min & 0.36 & 0.01 & 0.21 & 0.38 & 0.31 \\
Avg. & 1.20 & 8.32 & 0.53 & 1.27 & 1.87 \\
\hline
\end{tabular}

direction depends mainly on lateral compressive stress and is not significantly related to the stress level. The maximum strain development of constant amplitude fatigue follows an obvious three-stage rule, which is defined by the crack initiation, crack stable expansion, and crack propagation. The ratio of these three stages has a great correlation with the lateral pressure level, especially at a high lateral pressure, and the second stage of the maximum strain development is obviously longer, while the third stage becomes shorter and the specimen rapidly deteriorates. The strain development law $[18,19]$ follows the same pattern for uniaxial fatigue residual strain, but the value of the fatigue residual strain is larger than uniaxial. Under variable amplitude fatigue loads, the fatigue residual strain is not associated with the loading process. Development of fatigue residual strain is stable whether under variable amplitude loading or constant amplitude loading. The same is true for specimens loaded in the uniaxial direction.

Based on Figure 4, regression equations under different lateral stress ratios were analyzed using a nonlinear regression method for residual strain $\varepsilon_{r}$ and relative fatigue cycle $n / N$ as shown:

$$
\begin{gathered}
\varepsilon_{r}=109.0\left(\frac{n}{N}\right)^{3}-220.0\left(\frac{n}{N}\right)^{2}+164.6\left(\frac{n}{N}\right) \\
\frac{\sigma_{2}}{f_{c}}=0.25, \frac{\sigma_{3}}{f_{c}}=0.25, \\
\varepsilon_{r}=173.9\left(\frac{n}{N}\right)^{3}-328.1\left(\frac{n}{N}\right)^{2}+236.0\left(\frac{n}{N}\right) \\
\frac{\sigma_{2}}{f_{c}}=0.25, \frac{\sigma_{3}}{f_{c}}=0.50, \\
\varepsilon_{r}=246.7\left(\frac{n}{N}\right)^{3}-442.9\left(\frac{n}{N}\right)^{2}+302.7\left(\frac{n}{N}\right) \\
\frac{\sigma_{2}}{f_{c}}=0.50, \frac{\sigma_{3}}{f_{c}}=0.50 .
\end{gathered}
$$

Correlation coefficients $R^{2}$ of the above equations are, respectively, $0.976,0.976$, and 0.943 , all the values of $R^{2}$ are greater than 0.90, and it indicates that Formulas (3a), (3b), and $(3 c)$ are suitable to express the fatigue T-C-C failure criterion. If relative fatigue cycle $n / N=1$, the extreme fatigue residual strain $\varepsilon_{r}^{0}$ of concrete is, respectively, $53.6 \mu, 81.8 \mu$, and $106.5 \mu$. The extreme residual strain $\varepsilon_{r}^{0}$ can be used as a criterion to judge the fatigue damage of plain concrete in corresponding lateral stress ratio.

4.2. Fatigue Damage Model and Validation. According to the basic concepts of damage mechanics and the development laws of residual strain on PC under T-C-C and uniaxial fatigue loading, the fatigue damage was defined as the ratio between the residual strain of concrete $\varepsilon_{r}$ and the extreme fatigue residual strain $\varepsilon_{r}^{0}, \varepsilon_{r} / \varepsilon_{r}^{0}$. The damage equation is given by

$$
D=\frac{\varepsilon_{r}}{\varepsilon_{r}^{0}}=a\left(\frac{n}{N}\right)^{3}+b\left(\frac{n}{N}\right)^{2}+c\left(\frac{n}{N}\right),
$$

where $a, b, c$ are coefficients of the damage equation and relate to fatigue loading method and extreme fatigue residual strain. The relationships between the fatigue damage $D$ and relative number $n / N$ of plain concrete under T-C-C loading are shown in Figure 6. Above all, the proposed fatigue damage model can be used for multistage fatigue cumulative damage analysis of plain concrete in uniaxial and T-C-C loading. This analysis can also be used to predict remaining fatigue life of the sample.

The equivalent damage value $D_{e}$ and residual fatigue life prediction value $N_{2 e}$ or $N_{3 e}$ of PC at the lateral compressive stress ratio of 0.50 under T-C-C loading are shown in Table 4; $n_{20}$ is the fatigue life of the residual strain under twostage loading; $n_{10} / N_{1 e}$ and $n_{20} / N_{2 e}$ are the corresponding relatively equivalent fatigue life of $\varepsilon_{r 1}$ and $\varepsilon_{r 2} ; N_{2 e}\left(N_{3 e}\right)$ is the remaining fatigue life prediction value (including $\left.n_{20}\right) ; D_{e}$ is the equivalent damage value, $D_{e}=n_{1} / N_{1 e}+n_{2} / N_{2 e}$ is the remaining fatigue life.

As shown in Table 4, samples tested with variable amplitude fatigue loading had a maximum equivalent damage value $D_{e}$ of 1.92 , a minimum of 0.65 , and an average of 1.08. In comparison, the maximum damage value $D$ of the $\mathrm{P}-\mathrm{M}$ criterion (Table 3 ) is 7.61 , the minimum is 0.31 , and the average is 1.87 (not including the residual fatigue life of specimens with more than 2.5 million cycles). Meanwhile, the remaining fatigue life prediction values $N_{2 e}$ (two-grade fatigue) or $N_{3 e}$ (three-grade fatigue) are relatively close to the actual remaining fatigue life $n_{2}$ or $n_{3}$ in Table 2 . Figure 7 takes $N_{2 e}, N_{3 e}$ and $n_{2}, n_{3}$ logarithmic, makes $\lg N_{2 e}\left(\lg N_{3 e}\right)$ ordinate, makes $\lg n_{2}\left(\lg n_{3}\right)$ an abscissa, and converts the remaining fatigue life prediction values and the corresponding actual values into a scatter plot. If the scatter points are near the diagonal line on both sides, the forecast and experiment values of theory are satisfactory. As shown, the damage model proposed here is sufficiently accurate.

Based on the residual strain $\varepsilon_{r}$ and relative fatigue cycles $n / N$ of (3a), (3b), and (3c), the regression equation under 


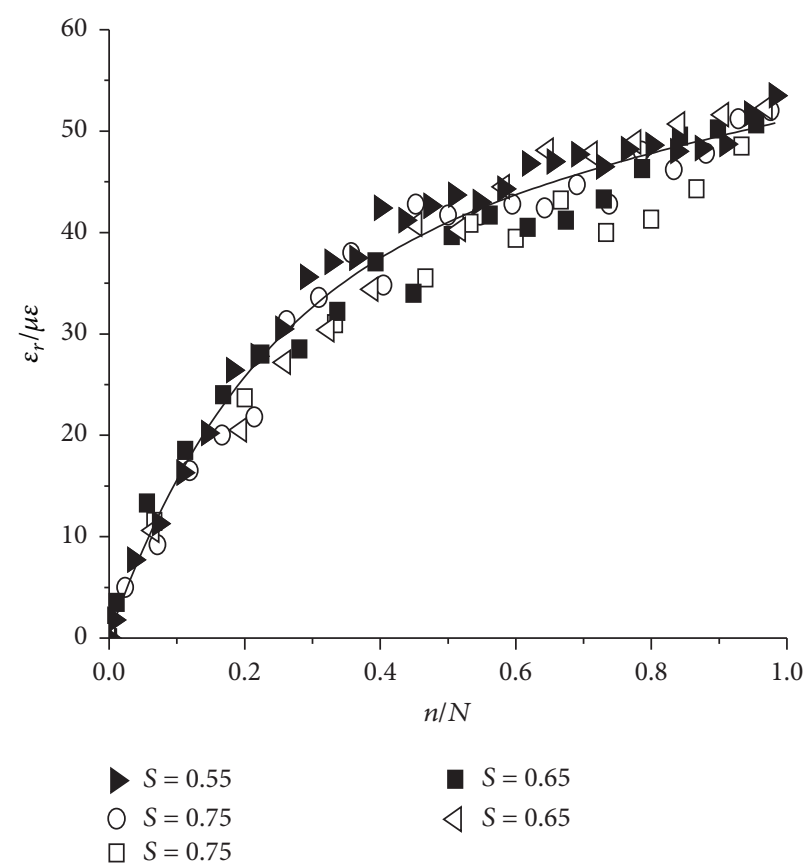

(a) $\sigma_{2} / f_{c}=0.25 ; \sigma_{3} / f_{c}=0.25$

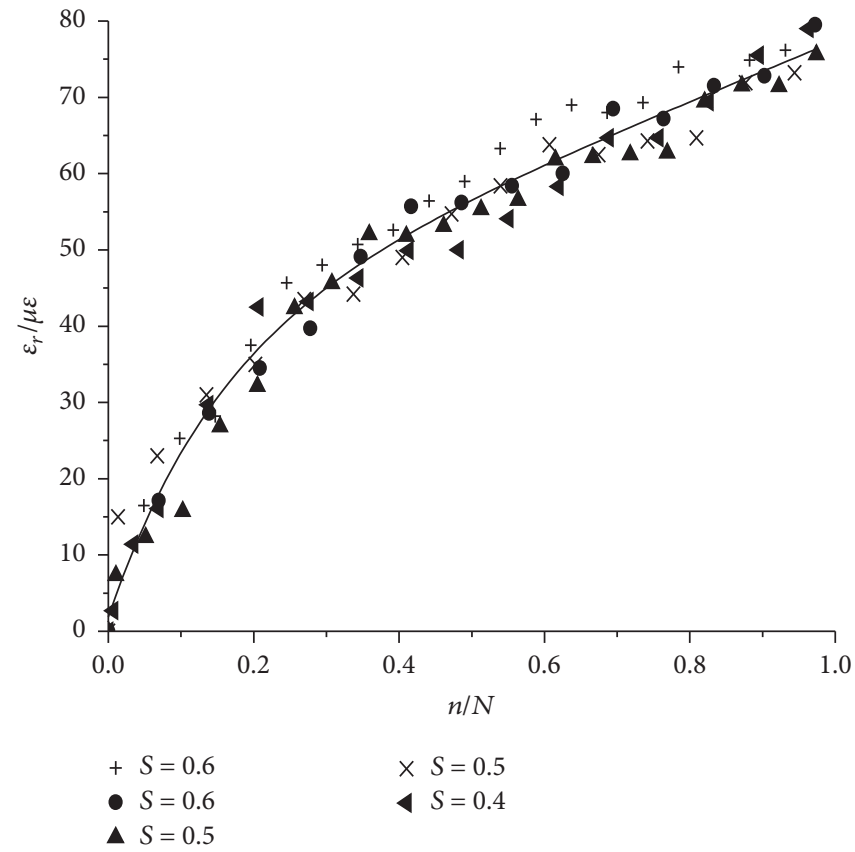

(b) $\sigma_{2} / f_{c}=0.25 ; \sigma_{3} / f_{c}=0.50$

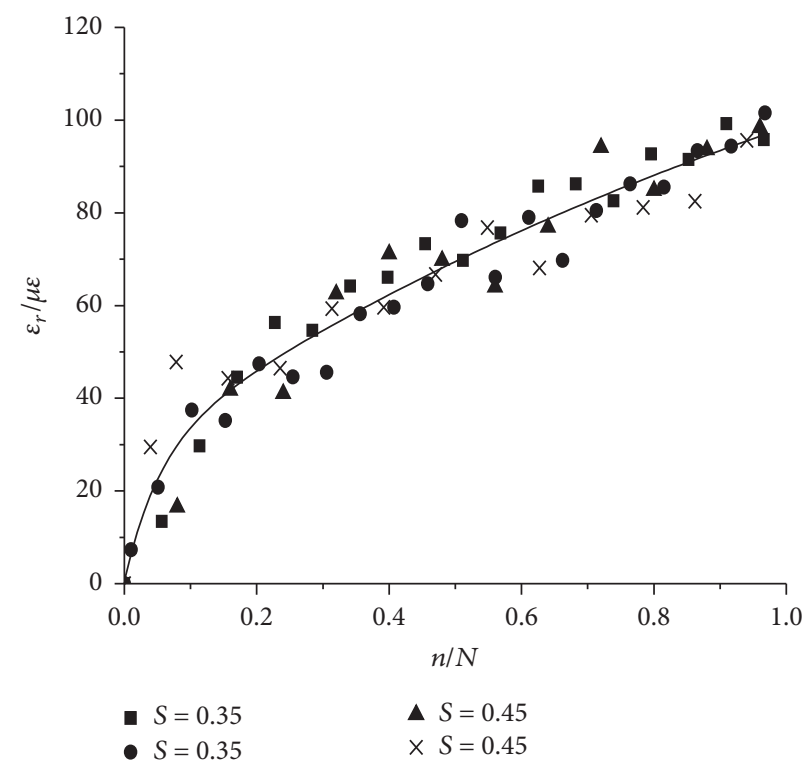

(c) $\sigma_{2} / f_{c}=0.50 ; \sigma_{3} / f_{c}=0.50$

FIGURE 4: Relationship of residual strain and relative fatigue cycle in T-C-C constant amplitude loading.

different lateral stress ratios was analyzed using nonlinear regression as shown below:

$$
\begin{aligned}
D & =\left\{\left(-\frac{1.24 \sigma_{2}}{f_{c}}+\frac{0.04 \sigma_{3}}{f_{c}}+2.60\right)\left(\frac{n}{N}\right)^{3}\right. \\
& +\left(\frac{1.82 \sigma_{2}}{f_{c}}+\frac{1.34 \sigma_{3}}{f_{c}}-5.32\right)\left(\frac{n}{N}\right)^{2} \\
& \left.+\left(-\frac{0.58 \sigma_{2}}{f_{c}}-\frac{1.39 \sigma_{3}}{f_{c}}+3.72\right)\left(\frac{n}{N}\right)\right\} .
\end{aligned}
$$

Using (5), Figure 8 shows the relationships between the damage variable $D$ and lateral compressive stress of $\sigma_{2} / f_{c}$, $\sigma_{3} / f_{c}$ as well as the spatial relationships in different relative cycle ratios of fatigue $(n / N=0.2,0.4,0.6,0.8)$. The figure axes are the damage variable $D$ and the lateral compressive stress ratios $\sigma_{2} / f_{c}, \sigma_{3} / f_{c}$, respectively.

\section{Discussion}

So far, there have been a lot of researches on uniaxial and multiaxial fatigue of concrete subjected to variable amplitude 


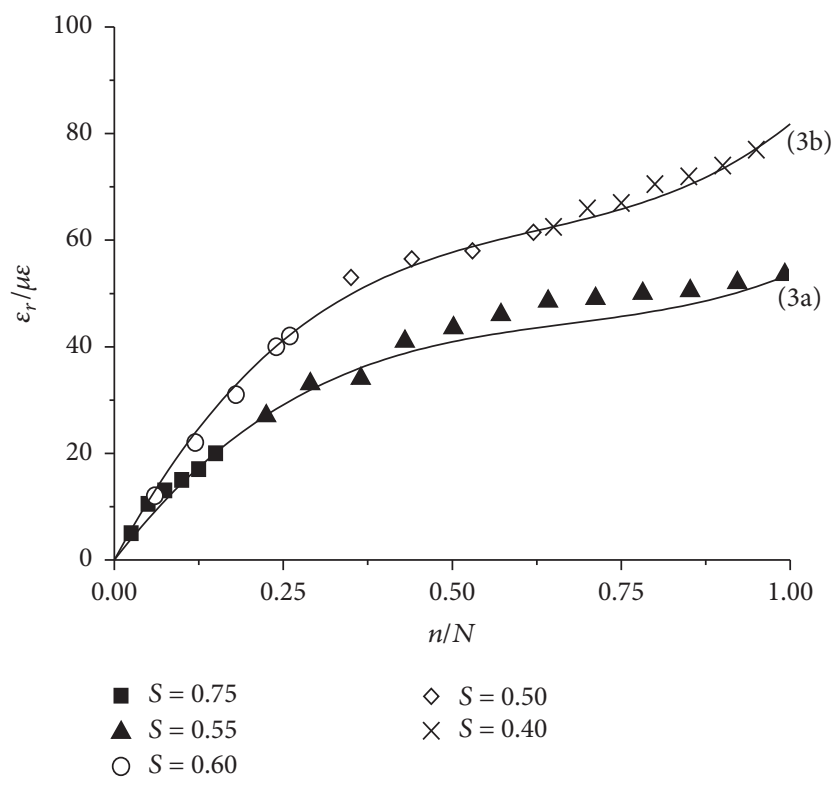

FIGURE 5: Relationship of residual strain and relative fatigue cycle in $\mathrm{T}-\mathrm{C}-\mathrm{C}$ variable amplitude loading.

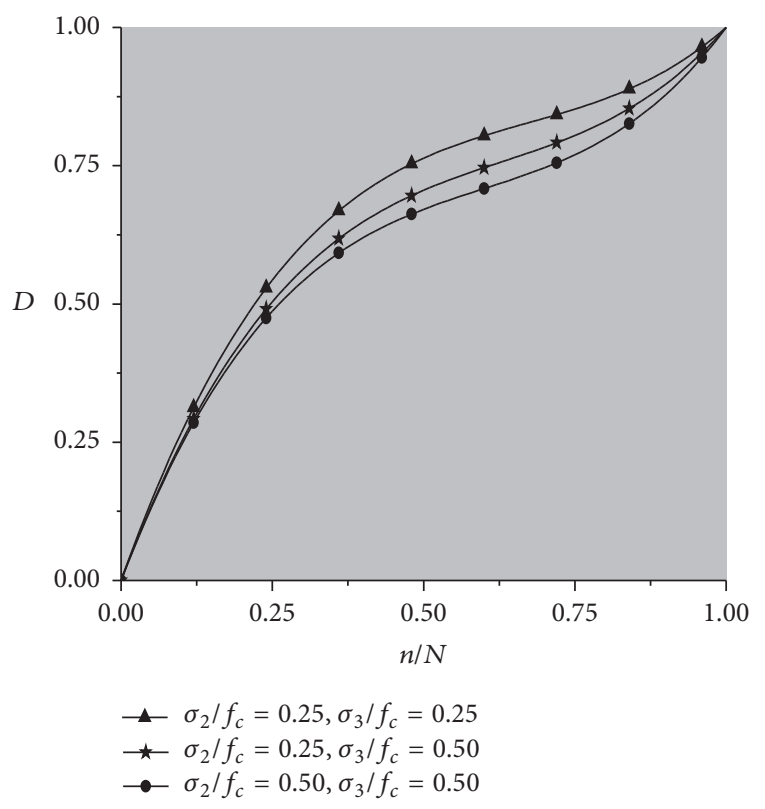

FIGURE 6: Relationship between damage and relative fatigue cycles $n / N$ in T-C-C loading case.

compression, while little attention has been paid to biaxial and triaxial tension and compression fatigue. The main reason is that the concrete specimen is difficult to achieve repeated tension-compression loading, and the testing key technology is not complete.

(1) For the multiaxial fatigue test, the physical centering of the sample is very important in the process of installation and testing and is more difficult than in a triaxial fatigue test. Poor alignment will result

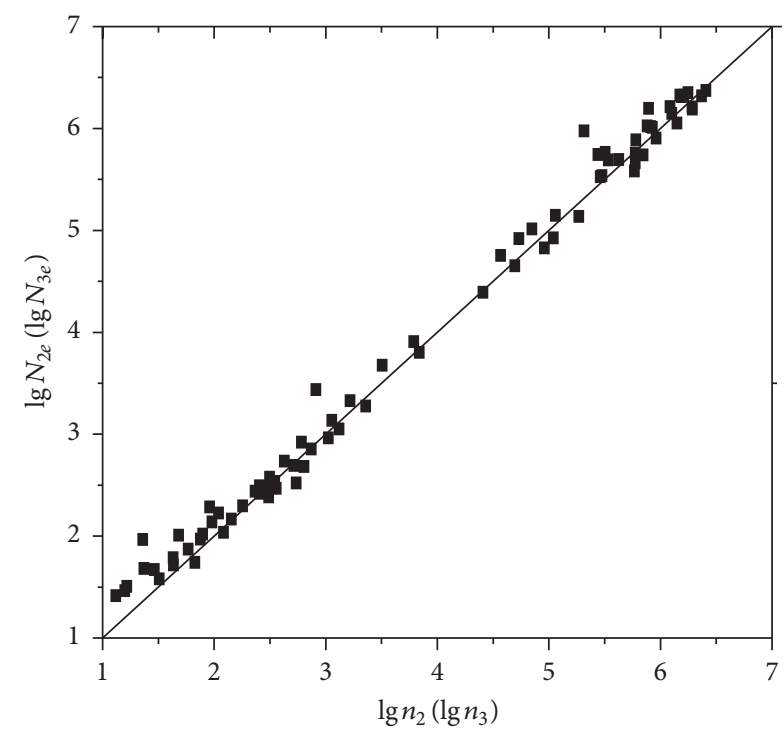

FIGURE 7: Comparison between predicted residual fatigue life and observed ones.

TABLE 4: Variable amplitude fatigue life of prediction.

\begin{tabular}{|c|c|c|c|c|c|}
\hline $\begin{array}{l}\text { Specimen } \\
\text { number }\end{array}$ & $D_{e}$ & $N_{2 e}$ & $\begin{array}{c}\text { Specimen } \\
\text { number }\end{array}$ & $D_{e}$ & $N_{3 e}$ \\
\hline 25250101 & 0.88 & 48 & 25250301 & 1.44 & 109 \\
\hline 25250102 & 1.37 & 241 & 25250302 & 0.94 & 93 \\
\hline 25250103 & 0.88 & 303 & 25250303 & 0.93 & 26 \\
\hline 25250104 & 0.91 & 52 & 25250304 & 1.29 & 293 \\
\hline 25250105 & 1.09 & 479 & 25250305 & 1.06 & 47 \\
\hline 25250201 & 0.89 & 1037225 & 25250401 & 1.51 & 2113472 \\
\hline 25250202 & 0.91 & 136286 & 25250402 & 0.76 & 343910 \\
\hline 25250203 & 0.87 & 140203 & 25250403 & 1.11 & 102601 \\
\hline 25250204 & 1.01 & 67159 & 25250404 & 1.00 & 44838 \\
\hline 25250205 & 1.36 & 1548276 & 25250405 & 0.72 & 84152 \\
\hline 25500101 & 0.80 & 168 & 25250301 & 0.84 & 55 \\
\hline 25500102 & 0.91 & 32 & 25250302 & 1.27 & 376 \\
\hline 25500103 & 0.98 & 61 & 25250303 & 1.53 & 29 \\
\hline 25500104 & 1.29 & 274 & 25250304 & 0.85 & 38 \\
\hline 25500105 & 0.82 & 74 & 25250305 & 1.28 & 146 \\
\hline 25500201 & 0.97 & 2350852 & 25250401 & 1.09 & 572043 \\
\hline 25500202 & 1.13 & 549963 & 25250402 & 1.45 & 1635711 \\
\hline 25500203 & 0.78 & 458977 & 25250403 & 1.22 & 335639 \\
\hline 25500204 & 1.33 & 2245031 & 25250404 & 0.97 & 579068 \\
\hline 25500205 & & & 25250405 & & \\
\hline 50500101 & 1.55 & 916 & 50500201 & 0.98 & 490733 \\
\hline 50500102 & 1.76 & 330 & 50500201 & 1.92 & 382615 \\
\hline 50500103 & 0.67 & 137 & 50500201 & 1.35 & 24700 \\
\hline 50500104 & 0.65 & 542 & 50500201 & 0.77 & 82501 \\
\hline 50500105 & 1.04 & 2134 & 50500201 & 0.63 & 56662 \\
\hline
\end{tabular}

Note. $D_{e}$ is equivalent damage value; $N_{2 e} / N_{3 e}$ is the residual fatigue life prediction values. 


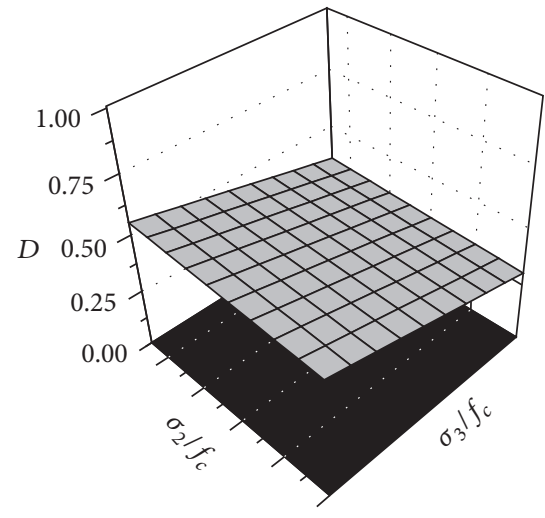

(a) $n / N=0.2$

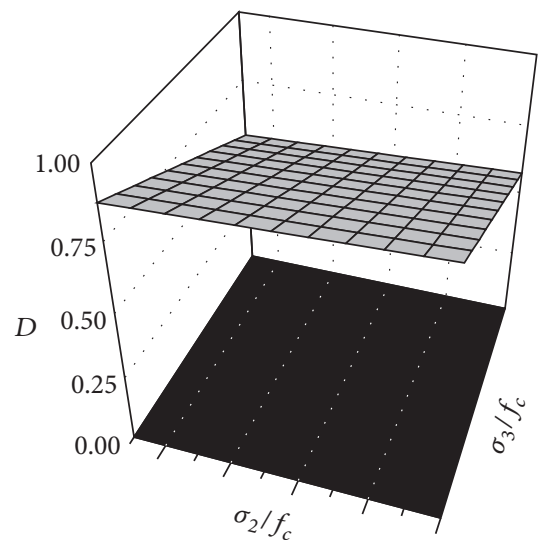

(c) $n / N=0.6$

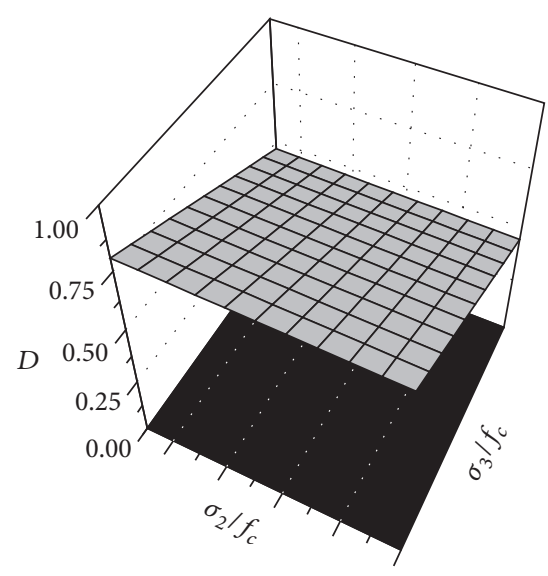

(b) $n / N=0.4$

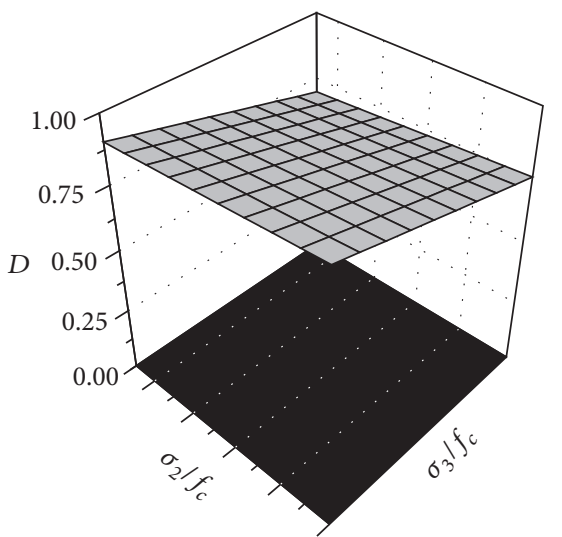

(d) $n / N=0.8$

FIGURE 8: Relationship between damage $D$ and $\sigma_{2} / f_{c}, \sigma_{3} / f_{c}$.

in specimen failure and consequently failure of the experiment. During testing, specimens were placed in the appropriate position and visually aligned before applying a $10 \mathrm{kN}$ static preload in the vertical direction. Moreover, a larger static load was applied to the specimens to center the samples horizontally. Finally, the sample was preloaded in the same proportions more than three times in three directions to verify centering in the test apparatus. Preload levels were then increased to $20 \sim 30 \mathrm{kN}$ to ensure contact between the loading plate and the specimen. Next, specimens were held in this centered position by gradually and evenly tightening eight screws at the upper and lower edges of the specimen. Fatigue tests were suspended after a dozen cyclic loads, to analyze the output of the deformation data in each direction and verify consistency. Finally, a small hammer was used to tap specimens or load heads as needed to adjust mechanical alignment through rotation of the globe hinge of the specimen in order to obtain valid data.

(2) As the testing system uses electrohydraulic servo control technology, the system is easily self-excited. Even the original MTS single-axis fatigue testing machine can appear self-excited during testing. Here, self-excitation refers to the system suddenly operating at a different frequency compared to the load frequency during normal operation or the ability to adjust the loading frequency to produce substantial vibration. To avoid mechanical resonance, the experiment should begin at a lower frequency running for a period of time, so that the direction of the installation of the specimen can be verified. The frequency can be smoothly increased to the ideal test frequency. The system has load control and displacement control in two directions; thus, each direction should be treated similarly to avoid self-excitation. Finally, the test system must be completely independent of the power supply to eliminate interference with other electrical equipment.

\section{Conclusions}

Based on analysis of experimental results from the development of fatigue strain, the following conclusions can be drawn below.

(1) The development of fatigue residual strain in the fatigue loading direction of PC under triaxial T-C-C 
constant amplitude cyclic loading is mainly dependent on the lateral compressive stress ratio and is mostly independent of stress level. The fatigue residual strain under variable amplitude fatigue loading was found to be associated with the relative fatigue cycle and lateral compressive stress ratio but is independent of the loading process. Strain development is as stable as the constant loading amplitude.

(2) The residual strain $\varepsilon_{r}$ and fatigue relative cycle $n / N$ were used to develop a nonlinear regression model. The ultimate residual strains $\varepsilon_{r}^{0}$ of concrete fatigue damage are, respectively, $53.6 \mu, 81.8 \mu$, and $106.5 \mu$. This can be used as a criterion to judge the fatigue damage of plain concrete in corresponding lateral stress ratios.

(3) Relative residual strain was defined as the damage variant, a damage evolution for plain concrete was proposed, and models for damage analysis and prediction of fatigue life were executed. The failure models developed can be used to predict the residual remaining life of plain concrete under multiaxial fatigue loads. Model predictions and the measured results are in good agreement.

(4) It is proved that Miner's rule is not applicable to multiaxial loading of plain concrete and has certain limitations for calculating multiaxial amplitude fatigue.

\section{Competing Interests}

The authors declare that they have no competing interests.

\section{Acknowledgments}

The present work was supported by the National Natural Science Foundation of China (no. 51378045) and Open Research Fund Program of Engineering Structure and New Materials of Beijing University Engineering Research Center (Beijing University of Civil Engineering and Architecture). The authors acknowledge the mentioned financial support gratefully.

\section{References}

[1] S.-J. Park, G.-K. Park, H. J. Yim, and H.-G. Kwak, "Evaluation of residual tensile strength of fire-damaged concrete using a non-linear resonance vibration method," Magazine of Concrete Research, vol. 67, no. 5, pp. 235-246, 2015.

[2] Z.-J. He, W.-L. Cao, J.-X. Zhang, and L. Wang, "Multiaxial mechanical properties of plain recycled aggregate concrete," Magazine of Concrete Research, vol. 67, no. 8, pp. 401-413, 2015.

[3] Z.-J. He and J.-X. Zhang, "Strength characteristics and failure criterion of plain recycled aggregate concrete under triaxial stress states," Construction and Building Materials, vol. 54, pp. 354-362, 2014.

[4] J. Mun, K. Yang, and S. Kim, "Tests on the compressive fatigue performance of various concretes," Journal of Materials in Civil Engineering, vol. 28, no. 10, 2016.
[5] L. Shi, L. Wang, Y. Song, and L. Shen, "Dynamic properties of large aggregate concrete under triaxial loading," Magazine of Concrete Research, vol. 67, no. 6, pp. 282-293, 2015.

[6] K. V. Subramaniam, J. S. Popovics, and S. R. Shah, "Fatigue response of concrete subjected to biaxial stresses in the compression-tension region," ACI Materials Journal, vol. 96, no. 6, pp. 663-669, 1999.

[7] S. Shiming and S. Yupu, "Dynamic biaxial tensile-compressive strength and failure criterion of plain concrete," Construction and Building Materials, vol. 40, pp. 322-329, 2013.

[8] D. Yan, G. Lin, and G. Chen, "Dynamic properties of plain concrete in triaxial stress state," ACI Materials Journal, vol. 106, no. 1, pp. 89-94, 2009.

[9] J. H. Yang, D. F. Zhao, and Y. P. Song, "A study on variableamplitude fatigue test and damage of concrete in tension and under multi-lateral pressures," China Civil Engineering Journal, vol. 38, no. 9, pp. 37-44, 2005 (Chinese).

[10] L. Peiyin, L. Qingbin, and S. Yupu, "Behavior of concrete under nonproportional biaxial fatigue stresses with one constant," ACI Materials Journal, vol. 104, no. 1, pp. 3-12, 2007.

[11] J. Y. Chen, Z. X. Zhang, H. W. Dong, and J. Zhu, "Experimental study on dynamic damage evolution of concrete under multiaxial stresses," Engineering Failure Analysis, vol. 18, no. 7, pp. 1784-1790, 2011.

[12] H. O. Byung, "Cumulative damage theory of concrete under variable-amplitude fatigue loadings," ACI Materials Journal, vol. 88, no. 1, pp. 41-48, 1991.

[13] W. Cao, Y.-P. Song, and H.-C. Liu, "Fatigue properties of plain concrete under triaxial variable-amplitude tensioncompression cyclic loading," Engineering Mechanics, vol. 23, no. 3, pp. 31-117, 2006 (Chinese).

[14] MTCDS, GB/T 17671-1999: Standard for the Test Method on Cements for Determination of Strength, MTCDS, Beijing, China, 1999 (Chinese).

[15] NSCGPRC, "Standard for test method of mechanical properties on ordinary concrete," GB/T 50081-2002, NSCGPRC, Beijing, China, 2003 (Chinese).

[16] D. Zhao, Y. Song, and M. Li, "Multiaxial fatigue experimental apparatus of concrete and relevant technics," Chinese Journal of Rock Mechanics and Engineering, vol. 23, no. 2, pp. 187-191, 2004.

[17] M. A. Miner, "Cumulative damage in fatigue," Transactions of the ASME, vol. 67, pp. 159-164, 1945.

[18] H.-S. Shang, S.-T. Yang, and X.-Y. Niu, "Mechanical behavior of different types of concrete under multiaxial tensioncompression," Construction and Building Materials, vol. 73, pp. 764-770, 2014.

[19] H.-S. Shang and G.-J. Ji, "Mechanical behaviour of different types of concrete under multiaxial compression," Magazine of Concrete Research, vol. 66, no. 17, pp. 870-876, 2014.

[20] R. Tepfers, C. Friden, and L. Georgsson, "Study of the applicability to the fatigue of concrete of the palmgren-miner partial damage hypothesis," Magazine of Concrete Research, vol. 29, no. 100 , pp. 123-130, 1977.

[21] J. O. Holmen, "Fatigue of concrete by constant and variable amplitude tests," ACI Journal, vol. 75, no. 4, pp. 71-110, 1982. 


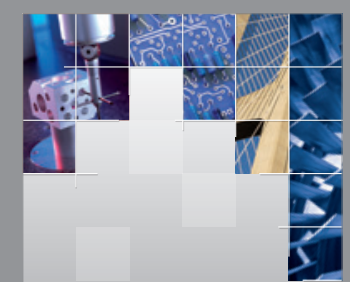

\section{Enfincering}
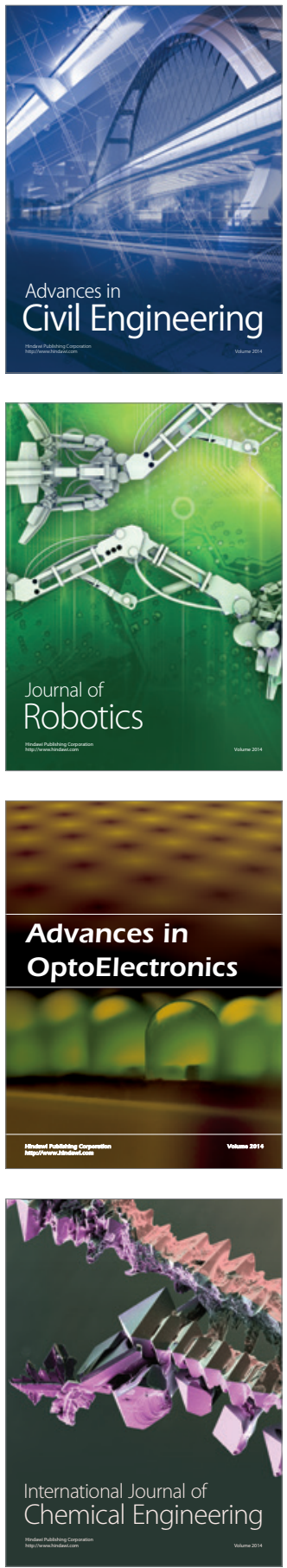

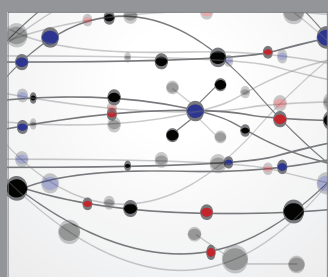

The Scientific World Journal

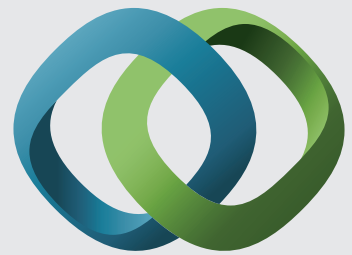

\section{Hindawi}

Submit your manuscripts at

https://www.hindawi.com
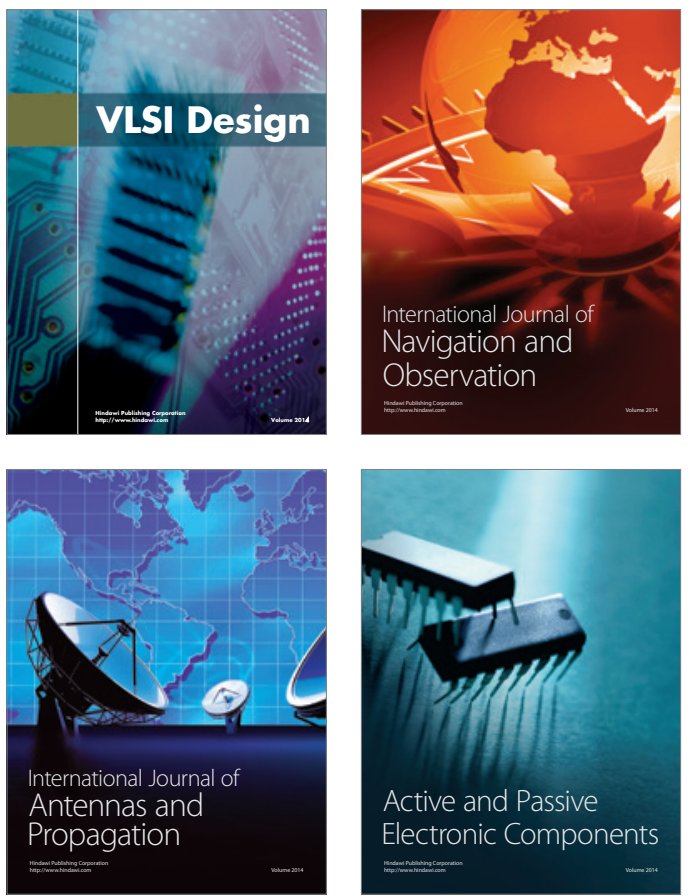
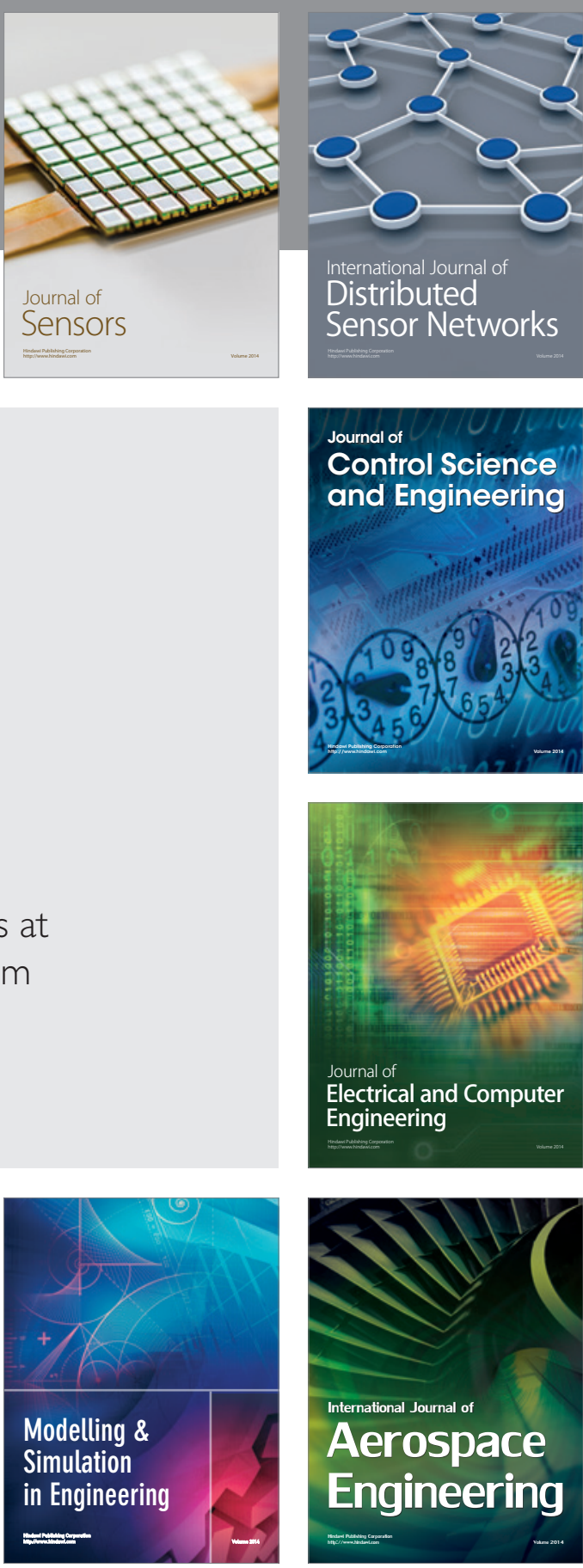

International Journal of

Distributed

Sensor Networks

$-$

Joumal of

Control Science

and Engineering
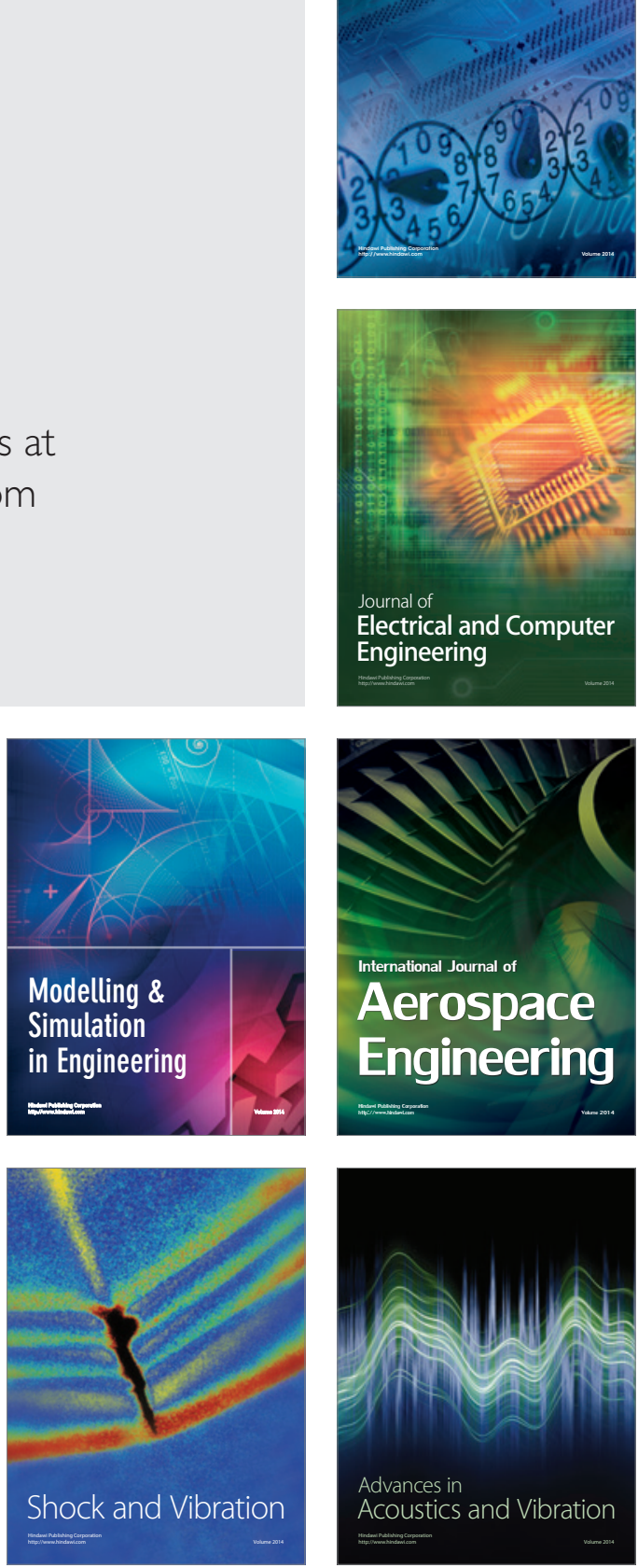